\title{
TOEPASSINGEN VAN WALABA OF BIJLHOUT 1)
}

\author{
DOOR
}

ir. W. SPOON

Walaba of bijlhout is een in Suriname veel voorkomende loofhoutsoort. Ook in de beide andere Guiana's treft men haar veelvuldig aan.

Meestal wordt voor walaba de botanische naam Eperua falcata $A u b l$. gebezigd 2) en vermoedelijk is dit ook wel de meest voorkomende soort van dit geslacht, maar daarnevens komen eenige andere soorten voor. Het Nederlandse Normaalblad N 1015 van November 1941 is dan ook voorzichtig en noemt als botanische herkomst van walaba of bijlhout: Eperua sp. div. Kort voordien had A. Ducke, verbonden aan de Botanische tuin te Rio de Janeiro, Brazilië, een overzicht opgesteld van het geslacht Eperua, waarbij hij 11 soorten onderscheidt ${ }^{3}$ ). De soort, die het meeste bekend is in de Guiana's en het vermaarde walaba- (of zoals de Engelsen schrijven wallaba-) hout levert, is volgens hem Eperua falcata Aubl..

In de „Flora of Surinam”, welke te Utrecht onder leiding van prof. dr. A. A. Pulle, wordt samengesteld 4), worden door de bewerkster van de Papilionaceae, mej. G. J. H. Aмshoff, vijf soorten van het geslacht Eperua als in Suriname voorkomend beschreven. Dat zijn E. falcata Aubl., E. rubiginosa Miq., E. Schomburgkiana Benth., E. grandiflora Benth. en E. Jenmani Oliver.

Enkele van die namen treffen wij dan ook aan in de door prof. dr. G. Stahel tijdens de oorlog in Paramaribo samengestelde monstercollectie van Surinaamse houtsoorten (alles gedekt door

1) Tevens Bericht van de Afdeling Handelsmuseum van het Indisch Instituut no. 218.

2) Zie b.v. G. Stahel, Surinam Timbers, 38 (Paramaribo 1944).

3) Trop. Woods no. 62, 21 (1-6-1940).

4) Tevens Meded. Afd. Handelsmuseum II.

$$
-289-
$$

West Indische Gids xxviII 
herbarium), waarvan na de bevrijding ook het Indisch Instituut een exemplaar ten geschenke ontving ${ }^{1}$ ). Van de vier monsters walaba met verschillende locale namen determineerde het Utrechtse Herbarium (prof. dr. A. A. Pulle) het bijbehorende herbarium als volgt:

no. 22: zwarte walaba Eperua falcata Aubl.

no. 23: witte walaba

no. 66: baboen walaba

no. 334 : itoeli walaba

, , , ,

," ," ,"

Eperua Jenmani Oliver.

Voordien had ook reeds J. PH. Pfeiffer in het eerste deel van zijn boek ,De houtsoorten van Suriname” 2) (blz. 245 e.v.) onderscheid gemaakt tussen het echte of rode bijlhout, volgens hem geleverd door Eperua falcata Aubl., en het witte bijlhout, dat vermoedelijk afkomstig zou zijn van Eperua Schomburgkiana Benth. of Eperua Jenmani Oliver. In het tweede deel van zijn boek (Een onderzoek naar de technische eigenschappen van acht en twintig van de voornaamste houtsoorten) beschrijft PfeIfFer echter uitsluitend het hout van Eperua falcata, dus het volgens hem echte bijlhout of walaba.

Het hout 3), en dit geldt in het bijzonder voor het kernhout, is zeer duurzaam, daarbij sterk en hard (bouwhout). Het kernhout is donker roodbruin gekleurd, maar veelal ontsierd door olie-achtige strepen en vlekken. Door uitlogen in water is de substantie welke dit veroorzaakt echter weg te nemen. Het wordt verder gebruikt als dakbedekking in de vorm van door splijten verkregen plankjes (shingles of sirappen). Voorts is het een goed brandhout.

Wij hebben nu nagegaan of er nog andere richtingen zouden zijn, waarin walaba met succes is toe te passen. Een onderzoek van de literatuur, gecombineerd met eigen waarnemingen, voerde tot de volgende indeling: 1. Papiergrondstof; 2. Verkoling; 3. Looistofbron.

\section{Papiergrondstof.}

De bruikbaarheid van walaba als papierhout is reeds eerder onderwerp van studie geweest, in het bijzonder in Brits-Guiana.

1) Jaarverslag Indisch Instituut I945, 28.

2) Meded. Afd. Handelsmuseum 6 (1926/27).

3) Zie ook J. B. Artken, The Wallabas of British Guiana, Trop. Woods no. 23, 1 (1-9-1930). 
Omstreeks 1927 zijn voor dat doel stamstukken van een aantal houtsoorten uit dat land naar het Imperial Institute te Londen gezonden. Elk stamstuk was van herbariummateriaal vergezeld, dat door de Royal Botanic Gardens Kew op naam werd gebracht.

Het als ,wallaba” ingezonden materiaal werd daar herkend als Eperua falcata Aubl. De met dit hout verkregen resultaten nemen wij hier in tabel I over $\left.{ }^{1}\right)$. Ter vergelijking voegen wij daaraan toe de resultaten verkregen met hout van Acacia decurrens (wattle), geteeld op Java en onderzocht in het „Laboratorium voor Technische Botanie" te Delft 2), omdat die houtsoort onder de bestudeerde Indische loofhoutsoorten een goed figuur sloeg. Verder voegden wij enkele cijfers toe van beukenhout (Fagus silvatica L.), een in Europa veel gebezigde loofhoutsoort. Alle ontsluitingen zijn volgens het natronproces verricht (verhitten van de houtspaanders met natronloog of caustische soda - $\mathrm{NaOH}$ - onder druk):

T a bel I

Ontsluiting van walaba

\begin{tabular}{l|c|c|c|c}
\hline \multirow{2}{*}{ Houtsoort } & $\begin{array}{c}\text { vol. gew. } \\
\text { (s.g. lucht- } \\
\text { droog hout) }\end{array}$ & $\begin{array}{c}\text { vezellengte } \\
\text { mm }\end{array}$ & \multicolumn{2}{|c}{$\begin{array}{c}\text { opbrengst aan celstof, ber. } \\
\text { op het luchtdroge hout }\end{array}$} \\
\cline { 3 - 5 } & ongebleekt & gebleekt \\
\hline walaba & 0.84 & $0.6-2.0$, gem. 1.4 & $35 \%$ & $32 \%$ \\
Java-wattle & 0.61 & $0.3-1.0$ & $52 \%$ & $44 \%$ \\
beuk & 0.56 & $0.6-1.3$ & - & -
\end{tabular}

Volgens het Imperial Institute is uit de celstof of pulp een behoorlijke kwaliteit papier te vervaardigen, terwijl ook de bleking van de pulp goed verloopt. Daartegenover oordeelt het Imperial Institute het rendement van de ontsluiting (opbrengst aan celstof) naar verhouding gering. Vergelijking met de resultaten bij Java-wattle bevestigt dit. Het heeft dan ook tot 1939 geduurd alvorens men over plannen om in Brits-Guiana tot celstofbereiding uit walaba te geraken hoort ${ }^{3}$ ) en ongetwijfeld heeft de in dat jaar uitgebroken tweede wereldoorlog daarop invloed gehad. De bedoeling was niet om in Brits-Guiana papier te vervaardigen, maar om celstof uit te voeren, waarbij hoeveelheden van 200.000 long ton per jaar genoemd werden. Verwezenlijkt zijn die plannen niet. Daarbij moet nog bedacht worden,

1) Bull. Imp. Inst. 26, 7 (1928) en Trop. Woods no. 23, 3 (1-9-1930).

2) Ber. Afd. Handelsmuseum I88, 11 en 18.

3) Economist (London) $I 38,856$ (1940). 
dat het per slot van rekening gaat om celstof uit een loofhoutsoort, welk halffabrikaat nimmer de waarde heeft van celstof verkregen uit naaldhout.

\section{Verkoling.}

Verkoling van walaba is tijdens de vorige wereldoorlog in Suriname toegepast met de bedoeling het houtgas te winnen. De gasfabriek te Paramaribo kwam in 1917 steenkool te kort en heeft dit tekort toen aangevuld met walabahout. Enkele jaren is zelfs meer van dit hout dan van steenkool verwerkt, tot in 1922 de aanvoer van steenkool weder voldoende werd ${ }^{1}$ ). Opbrengst en kwaliteit van het gas uit walaba werden gunstig beoordeeld.

Verkoling van walaba ter bereiding van houtskool is in BritsGuiana vrij veel gedaan. De bevolking verkoolt deze (en enkele andere) houtsoorten nog op zeer eenvoudige manier, nl. in kuilen. Door het Imperial Institute te Londen is reeds tijdig een onderzoek ingesteld naar de kwaliteit van dergelijke door de bevolking gewonnen walaba-houtskool 2).

In het volgende tabelletje is de uitslag van het onderzoek opgenomen, waaraan wij ter vergelijking hebben toegevoegd het resultaat van onderzoek in ons scheikundig laboratorium van enkele houtskoolmonsters 3 ), te weten één uit Suriname (H.M. no. 2817-2) en één van Java (H.M. no. 4665), beide eveneens genomen uit door de bevolking ter plaatse bereid product. De locale en wetenschappelijke namen van de beide walaba's zijn overgenomen uit het verslag van het Imperial Institute.

T a be 1 II

Samenstelling van walaba-houtskool.

\begin{tabular}{|c|c|c|c|c|c|c|c|c|c|}
\hline \multicolumn{4}{|c|}{ houtsoort } & \multicolumn{6}{|c|}{ houtskool, luchtdroog } \\
\hline $\begin{array}{l}\text { locale } \\
\text { naam }\end{array}$ & herkomst & $\begin{array}{c}\text { weten- } \\
\text { schappe- } \\
\text { lijke naam }\end{array}$ & $\mid \begin{array}{c}\text { s.g. lucht- } \\
\text { droog }\end{array}$ & $\begin{array}{c}\text { vocht } \\
\%\end{array}$ & $\begin{array}{l}\text { as } \\
\%\end{array}$ & $\begin{array}{c}\text { vluch- } \\
\text { tig } \\
\%\end{array}$ & $\begin{array}{l}\text { vol. } \\
\text { gew. }\end{array}$ & $\begin{array}{c}\text { s.g. } \\
\text { schijn- } \\
\text { baar }\end{array}$ & $\begin{array}{c}\text { verbran- } \\
\text { dings- } \\
\text { warmte }\end{array}$ \\
\hline $\begin{array}{l}\text { Soft } \\
\text { wallaba }\end{array}$ & Br. Guiana & $\begin{array}{r}\text { Eperua } \\
\text { falcata }\end{array}$ & $0.85-0.94$ & 4.94 & 1.00 & 17.20 & 0.395 & 0.64 & 7320 cal. \\
\hline $\begin{array}{l}\text { Ituri } \\
\text { wallaba }\end{array}$ & idem & $\begin{array}{l}\text { Eperua } \\
\text { Jenmani }\end{array}$ & idem & 5.59 & 0.99 & 34.00 & 0.38 & 0.70 & $6450 \mathrm{cal}$ \\
\hline $\begin{array}{l}\text { tama- } \\
\text { rinde }\end{array}$ & Suriname & $\begin{array}{l}\text { Pitheco- } \\
\text { lobium sp. }\end{array}$ & $0.57-0.82$ & 6.8 & 4.7 & 13.6 & - & 0.60 & 一 \\
\hline wattle & Java & $\left|\begin{array}{l}\text { Acacia } \\
\text { decurrens }\end{array}\right|$ & $0.6-0.9$ & 5.8 & 0.9 & 25.8 & 0.26 & 0.50 & 一 \\
\hline
\end{tabular}

1) Voor uitvoeriger beschrijving zie Ber. Afd. Handelsmuseum 2I2, 2, ook verschenen in Ned. Bosbouw T. I8, 273 (1946) en I9, 17 (1947).

2) Bull. Imp. Inst. 28, 138 (1930) en Trop. Woods no. 23, 4 (1-9-1930).

3) Ber. Afd. Handelsmuseum I85, 6 en $212,14$. 
Zoals de bereiding liet verwachten, bevatte de kool nogal wat vluchtige bestanddelen. Toch voldeed de walaba-kool nog alleszins bevredigend als generatorbrandstof voor vrachtauto's, hoewel aanvankelijk met vrij dichte rook, die de filters extra belastte; vollediger verkoling met dus minder vluchtige bestanddelen zou derhalve aanbeveling verdienen. Voor landen als de Guiana's, waar geen aardolie voorkomt, blijft het immers altijd van belang te weten uit welke andere grondstoffen het dan wel motorbrandstof kan verkrijgen (in dit geval hout, dat er overvloedig aanwezig is). Tevens dient dan verontreiniging van de houtskool met aarde en zand voorkomen te worden, zoals ongetwijfeld bij het monster uit Suriname, gezien het abnormale asgehalte ad $4.7 \%$, het geval was.

In verband met een dergelijk gebruik van walaba-houtskool is het verder van belang te weten of en zo ja welke bijproducten van de verkoling met voordeel te winnen zouden zijn. In het scheikundig laboratorium van de Afdeling Handelsmuseum is daaromtrent een apparatuur uitgewerkt ${ }^{1}$ ), in onderstaande tabel laten wij enkele uitkomsten volgen.

T a be 1 III

Verkolingsproeven te Amsterdam opbrengst in \% van het luchtdroge hout.

\begin{tabular}{l|l|c|c|c|c}
\hline H.M. no. & houtsoort & houtskool & teer, ruw & azijnzuur & methanol \\
\hline 776 & walaba & 33.7 & 10.0 & 2.9 & 1.6 \\
4665 & Java-wattle & 27.6 & 12.3 & 5.0 & 1.6 \\
Zweden & beuk & 30 & $\begin{array}{c}4.2 \\
\text { (gereinigd) }\end{array}$ & 6.5 & 1.7
\end{tabular}

Wederom voegden wij de uitkomsten van enkele andere loofhoutsoorten ter vergelijking toe; beukenhout wordt in Europa veel voor droge destillatie gebezigd, de getallen zijn van een onderzoekingsinstituut te Stockholm 2). Het gebezigde monster walaba no. 776 stond in onze verzamelingen te boek als Eperua falcata.

Uit de tabel blijkt terstond, dat de verkoling van deze walabasoort geen bijzondere opbrengst aan bijproducten levert 3).

1) A. J. van Duuren, Chem. Weekbl. 42, 19 (1946).

2) Ber. Afd. Handelsmuseum 2I2, 10.

3) $\mathrm{Na}$ de oorlog heeft men in Engeland bijzondere aandacht gegeven aan de teer uit beukenhout als bron voor phenol en gesubstitueerde phenolen, het uitgangsmateriaal voor de vervaardiging van persmassa's (kunsthars) op phenolbasis - T.N.O. Nieuws 2, 109 (1947) —; misschien, dat zou blijken, dat ook de teer uit walaba in die richting waarde kan hebben. 
Speciaal de opbrengst aan houtzuur (azijnzuur) is laag, zoals bij de meeste tropische houtsoorten, een regel waarop het hout van Acacia decurrens (wattle) een der weinige uitzonderingen vormt.

Wel zal de walaba-kool zwaar en stevig kunnen zijn, gezien het vrij hoge soortelijke gewicht van het hout (0.85-0.94). Misschien hield de uitvoer van walaba-houtskool naar Engeland, waarmede in 1937 werd begonnen 1), daarmede verband. Een moeilijkheid was toen de verpakking, aangezien de houtskool door haar zure karakter de emballage aantastte. De houtskool werd door de bevolking bereid en wij zagen reeds in tabel II, dat bij de gevolgde werkwijze de verkoling vaak onvolledig was; vermoedelijk, dat daarin de oorzaak van de moeilijkheden gezocht moet worden. Van verdere uitvoer vinden wij geen melding gemaakt.

\section{Looistofbron.}

Walaba-hout bevat een waardevolle looistof. Deze uitspraak is het resultaat van een uitgebreid tijdens de oorlog in Nederland verricht onderzoek. In het kort laat zich dit als volgt samenvatten.

In 1939 heeft de heer J. W. GoNGGRYP in de Afdeling Handelsmuseum van het Indisch Instituut een onderzoek verricht naar het voorkomen van looistoffen in houtsoorten uit de Indische Archipel en uit Suriname. In 1940 was het orienterende onderzoek zover gevorderd, dat een vijftigtal houtsoorten op grond van hun looistofgehalte voor een uitgebreider onderzoek in aanmerking kwamen 2). Wij traden daartoe in overleg met het Lederinstituut T.N.O. te Waalwijk - destijds nog Rijksproefstation en Voorlichtingsdienst voor de leder- en schoenindustrie genaamd welk overleg in 1941 voerde tot looiproeven op semi-technische schaal met een tiental houtsoorten. Er was nl. voor zo'n onderzoek per houtsoort ongeveer $5 \mathrm{~kg}$ tot poeder gebracht hout nodig, hoeveelheden die wij in onze verzamelingen, waarvan als gevolg van de Duitse bezetting van Nederland geen aanvulling mogelijk was, niet voor alle soorten meer beschikbaar hadden. Eén der tien houtsoorten was walaba 3 ); van het ter beschikking staande

1) Report Forest Dept. Br. Guiana I937, 6.

2) Meded. Afd. Handelsmuseum 22, 30 (1941) (,,Inlichtingen en Onderzoekingen in 1940").

3) Ber. Afd. Handelsmuseum 176 , ook verschenen in Ned. LederInd., Techn. Bijblad 37I van 19-11-1941. 
hout (H.M. no. 776, Eperua falcata) had het kernhout de volgende samenstelling:

totaal in water oplosbaar . . . . . . . . . . 13.0\% waarvan looistof. . . . 7.9\%, niet-looistof. . . . $5.1 \%$

Uit dit kernhout werd door het proefstation met warm water een extract bereid, dat na concentratie in een speciaal indampapparaat tot $19.4^{\circ}$ Bé. de volgende samenstelling bleek te bezitten:

looistof. . . . . . 25.7\%, niet-looistof. . . . $11.1 \%$

Met het extract werden vervolgens kleine stukken rundsbloot (voor zoollederfabricage) gelooid. Het looirendement bedroeg $75 \%$; kwaliteit, uiterlijk beoordeeld, stand en kleur waren normaal.

Het proefstation oordeelde dan ook, dat er alle reden was om aan te nemen, dat het extract van walaba-kernhout geschikt zou zijn als volwaardig looimiddel in de praktijk te worden gebruikt.

In 1943 werd door een in Suriname belangstellende combinatie op dit resultaat teruggekomen, doordat men ons de vraag voorlegde of het mogelijk zou zijn met walaba een volledig semitechnisch looi-onderzoek op te zetten. Finantiële steun werd daarbij toegezegd. Bij overleg met het Lederinstituut T.N.O. bleek, dat voor een zodanig onderzoek tenminste $100 \mathrm{~kg}$ hout nodig zou zijn. Uit onze voorraden kon inderdaad $110 \mathrm{~kg}$ walaba (H.M. no. 776, Eperua falcata) beschikbaar worden gesteld. Voor de bereiding van het looiextract werd de medewerking verkregen van het Laboratorium voor Technische Botanie te Delft (prof. dr. G. van Iterson JR.); dit laboratorium beschikte nl. over de daartoe geeigende apparatuur. Het werk daar werd uitgevoerd door de heer J. J. BREEN.

Een moeilijkheid vormde aanvankelijk de verkleining van het hout, dat wij in de vorm van planken konden verstrekken. Looibasten (zoals eiken-, mangrove-, acacia of wattle-bast) worden vervezeld, een werkwijze, waartoe hout zich niet leent. Verkleinen hiervan door hakken en/of zagen geeft uiteindelijk een korrelig product, dat echter in aanraking met water gaat zwellen en samen ballen en zodoende gemakkelijk aanleiding geeft tot verstopping van de extractie-apparatuur. Na enig zoeken werd in Delft een oplossing gevonden door de planken in een bevriend laboratorium op een schaafbank tot kleine krullen te verwerken, welke krullen vervolgens in een houten vat met geperforeerde bodem, 
voorzien van een verwarmingsinrichting en van een pomp voor het circuleren van de vloeistof, met water bij een temperatuur van $80^{\circ} \mathrm{C}$ zijn uitgetrokken. Het extract is daarna in een vacuumpan (simple effect) bij circa $50^{\circ} \mathrm{C}$ ingedikt tot een concentratie van $25^{\circ}$ Bé.

Te Waalwijk zijn met dit extract looiproeven genomen, waarbij quebracho-extract als vergelijking werd gebruikt, omdat het walaba-extract in zijn eigenschappen daarmede veel overeenkomst vertoonde en het eveneens een pyro-catechine-looistof is.

Deze looiproeven verliepen voor het walaba-extract alleszins naar wens, zodat het Lederinstituut T.N.O. kon concluderen ,,in ieder geval kunnen wij de walaba-looistof een prima, volwaardige looistof noemen, die de quebracho volledig kan vervangen. De laboratorium-looiproeven van 1941 blijken dus door dit semi-technisch onderzoek volledig bevestigd te zijn. Ook het rendement bij de extractie is zeer gunstig".

Bij die extractie blijft een aanzienlijke hoeveelheid verkleind houtmateriaal achter. Terstond vraagt men zich af of dat nog waarde heeft en men denkt dan in de eerste plaats aan omzetting in celstof voor papierbereiding, omdat het reeds verkleind is. Maar die verkleining van hout ten behoeve van de looistofwinning geschiedt volgens geheel andere regels en gaat - zoals wij zagen - veel verder dan ten behoeve van de celstofbereiding gebruikelijk is, waarbij men juist tracht zoveel mogelijk de vezel te sparen. Dan betreft het hier een loofhoutsoort, terwijl de vraag voor papiercelstof in de eerste plaats naar de naald houtsoorten uitgaat. En tenslotte zagen wij in paragraaf 1, dat de celstof uit walaba geen zodanige kwaliteiten bezit, dat bijzondere vraag ernaar gerechtvaardigd zou zijn. Vermoedelijk zal dus de verwerking van walaba op looistof het zonder dit bijproduct moeten doen.

Zoeven hebben wij vermeld, dat het Lederinstituut T.N.O. het rendement van de extractie zeer gunstig oordeelde. Daarmede wordt bedoeld, dat de in het hout aanwezige looistof, die bij de analyse in het laboratorium kwantitatief wordt gewonnen, ook bij werken op praktijkbasis vrijwel volledig is te winnen.

Tot dusverre hebben wij slechts cijfers genoemd verkregen met het walaba-hout uit onze verzamelingen no. 776 (Eperua falcata) en daarvan weder het kernhout. Want het spinthout van walaba bevat veel minder looistof. Tijdens de bereiding van het looi-extract te Delft werd in het Laboratorium voor Technische 
Botanie tevens een vergelijkende analyse gemaakt van spint en kern afgescheiden uit het door ons voor de proef verstrekte houtmateriaal; het resultaat was als volgt:

\begin{tabular}{c|r|r}
\hline & spint & kern \\
\hline totaal in water oplosbaar & $8.26 \%$ & $13.27 \%$ \\
waarvan: looistof & $3.52 \%$ & $9.71 \%$ \\
niet-looistof & $4.74 \%$ & $3.56 \%$
\end{tabular}

De analyse van het kernhout komt overeen met onze in de aanvang van deze paragraaf vermelde analyse wat betreft het gehalte aan in water oplosbare stoffen $(13.0 \%)$, de verhouding van looistof tot niet-looistoffen is bij de nieuwe analyse zelfs nog wat gunstiger.

$\mathrm{Om}$ nu een vollediger beeld van het looistofgehalte te verkrijgen hebben wij na de bevrijding terstond moeite gedaan voor nieuwe monsters hout. Dank zij de medewerking van importeurs slaagden wij daarin al spoedig. Het resultaat van het onderzoek in ons scheikundig laboratorium door Mej. W. M. SEsseler, chem. dra., brachten wij in tabel IV bijeen. Tevens was Mej. Dr. A. Mennega van het Utrechts Herbarium zo vriendelijk de monsters op naam te brengen. Van alle monsters is slechts kernhout onderzocht, dat voor de analyse werd verkleind op de $5 \mathrm{~mm}$ zeef.

T a b e l IV

Looistof-analyses van monsters walaba uit Suriname, in \%.

\begin{tabular}{|c|c|c|c|c|c|c|}
\hline H.M. no. & $\begin{array}{l}\text { Wetenschap- } \\
\text { pelijke naam }\end{array}$ & $\begin{array}{c}\text { totaal } \\
\text { oplosbaar } \\
\text { (in water) }\end{array}$ & $\begin{array}{l}\text { looistof } \\
\text { (huid- } \\
\text { poeder) }\end{array}$ & $\begin{array}{l}\text { oplosbare } \\
\text { niet-looi- } \\
\text { stoffen }\end{array}$ & $\begin{array}{l}\text { onoplos- } \\
\text { bare } \\
\text { stoffen }\end{array}$ & water \\
\hline 776 & E. falcata & 13.0 & 7.9 & 5.1 & 80.8 & 6.4 \\
\hline 1727 & idem & 11.4 & 7.9 & 3.5 & 78.8 & 9.8 \\
\hline $5192-22$ & idem & 11.6 & 6.9 & 4.7 & 77.6 & 10.8 \\
\hline $5192-23$ & idem & 10.9 & 7.1 & 3.8 & 80.9 & 8.2 \\
\hline $5192-66$ & idem & 10.6 & 6.0 & 4.6 & 81.6 & 7.8 \\
\hline $5192-334$ & E. Jenmani & 4.8 & - & - & - & - \\
\hline $5278-1$ & E. falcata? & 6.3 & - & - & - & - \\
\hline $5278-2$ & $\begin{array}{l}\text { E. Schom- } \\
\text { burgkiana? }\end{array}$ & 3.2 & - & - & - & - \\
\hline 5294 & E. falcata & 9.1 & 3.7 & 5.4 & 80.9 & 10.0 \\
\hline $5337-4$ & E. Jenmani & 5.9 & 1.5 & 4.4 & 80.8 & 13.3 \\
\hline 5349 & E. falcata & 3.8 & 1.8 & 2.0 & 83.0 & 13.2 \\
\hline
\end{tabular}


Het resultaat van de arbeid van beide dames biedt enige verrassingen. Met een enkele uitzondering (no. 5349) bevatten de als Eperua falcata gedetermineerde monsters veel meer looistof dan die van Eperua Jenmani en Eperua Schomburgkiana. Bij no. 5278-1 tekent Mej. Mennega aan, dat dit monster veel op Eperua falcata gelijkt, maar toch op een aantal punten afwijkt; afgaande op het lage gehalte zou men geneigd zijn die afwijking te onderschrijven.

Een punt, dat uiterlijk bij de monsters opviel, was het verschil in intensiteit van de donkere olieachtige vlekken en strepen (welk verschijnsel wij in de aanvang van dit artikel als kenmerkend voor walaba beschreven). De monsters $5278-1$ en -2 , tegelijkertijd ontvangen, vertoonden slechts weinig vlekken en strepen; van de vier monsters uit de collectie Stahel (no. 5192) had no. 334 eveneens weinig vlekken, maar de nrs. 22, 23 en 66 (alle Eperua falcata) des te meer. Men krijgt de indruk, dat er verband is tussen de intensiteit van dit verschijnsel en het looistofgehalte. Aangezien de looistof in water oplosbaar is, zou dan tevens verklaard wezen, waarom men met uitlogen van walaba de hinderlijke vlekken en strepen kan doen verdwijnen.

In elk geval zal bij een eventuele exploitatie van walaba voor de looistof goed op de botanische herkomst gelet dienen te worden.

\section{S a m envat ting.}

Walaba of bijlhout, Eperua sp. div., heeft als papiergrondstof geen bijzondere kwaliteiten, het verschilt daarin niet van de meeste loofhoutsoorten.

Walaba levert bij verkoling een technisch bruikbaar houtgas en een goede kwaliteit houtskool, de opbrengst aan houtzuur (azijnzuur) is echter gering en daardoor weinig aantrekkelijk als nevenproduct.

Walaba bevat een waardevolle looistof, vooral in het kernhout. Niet bij alle soorten van het geslacht Eperua is het looistofgehalte echter even hoog, vermoedelijk is de soort Eperua falcata in dit opzicht de beste. 
Applications for wallaba

(Summary)

Wallaba is a broad-leaved tree widely distributed throughout Surinam and the other Guianas. Wallaba belongs to the genus Eperua, of which five species are described in the ,Flora of Surinam" (edited by dr. A. Pulle) viz. E. falcata Aubl., E. rubiginosa Miq., E. Schomburgkiana Benth., E. grandiflora Benth. and $E$. Jenmani Oliver.

Already in 1928 the Imperial Institute, London (Bulletin 26, 7) made a test on the suitability of wallaba as a paper-making material. The wood belonged to E. falcata and was treated with caustic soda. The results are given in table I; they indicate that the wood gives a pulp of good quality and readily bleachable, but that the yield is rather lower than from most timbers.

Wallaba burns well and is used throughout the Guianas for fuel. During the first world-war the gas-works at Paramaribo, Surinam, used it with success for the production of illuminating gas. As produced by the natives in sandpits the quality of the charcoal is rather poor, as shown in table II, the amount of volatile matter being too high. Still it may be used as a fuel in portable gas-plants, which is important for the Guianas where there is no petroleum. Therefore an investigation was made by the Royal Institute for the Indies, Amsterdam, on the amount of byproducts obtainable when burning wallaba. Table III gives the results; especially the amount of acetic acid is too low for a commercial production.

During the second world-war an investigation was made by the Institute for the Indies on the quality of the tannin occurring in the wood. The result was very encouraging, the tannin being of the same quality as quebracho. Not all species of Eperua contain the same amount of tannin, most probably $E$. falcata is the best in this respect. The wood remaining after the extraction of the tannin, has no value as a paper-making material as the fibre of it has been damaged too much in the necessary reduction of the wood.

Amsterdam, Juli 1947. 